\title{
Mucous Membrane Hemangioma
}

National Cancer Institute

\section{Source}

National Cancer Institute. Mucous Membrane Hemangioma. NCI Thesaurus. Code

C7744.

A hemangioma arising from the mucous membranes. 